\title{
Use of dietary supplements by pregnant women in Colombia
}

\author{
Robinson Ramírez-Vélez ${ }^{1 *}$, Jorge Enrique Correa-Bautista' ${ }^{1}$, Héctor Reynaldo Triana-Reina², \\ Emilio González-Jiménez ${ }^{3,4}$, Jacqueline Schmidt-RioValle ${ }^{3,4}$ and Katherine González-Ruíz ${ }^{5}$
}

\begin{abstract}
Background: During pregnancy, the need for certain nutrients increases. This study assessed the prevalence and socio-demographic factors associated with dietary supplement use in a representative sample of pregnant women in Colombia.

Method: Data for this study were obtained from a cross-sectional, nationally representative survey (ENSIN, 2010). A total of 1856 pregnant women, 13-49 years of age, were recruited. The use of prenatal dietary supplements (Vitamins A, C or E) was treated as a binary outcome (used at some time or never sued during pregnancy when prescribed by a doctor) in multinomial analyses. Sociodemographic data and associated factors were assessed by computer-assisted personal interview technology.
\end{abstract}

Results: Of the sample, 1123 women (68.6\%) reported taking prenatal dietary supplements at some stage during their pregnancy. Most users had a high socioeconomic level (79.5\%), were in their third trimester of pregnancy (79.5\%), were 30-49 years of age (74.0\%), and lived in the central region of Colombia (73.8\%). The multivariate logistic regression showed that third trimester of pregnancy (OR 6.2;95\% Cl 4.0 to 9.3), high educational level (OR 2.3; 95\% Cl 1.5 to 3.4), high socioeconomic level -SISBEN IV or more- (OR 2.0; $95 \%$ Cl 1.4 to 2.8), residence in the Atlantic region (north) (OR 2.6; $95 \% \mathrm{Cl} 1.7$ to 3.6), Eastern region (OR 2.0; $95 \% \mathrm{Cl} 1.3$ to 3.1), central region (OR 2.6; $95 \% \mathrm{Cl} 1.7$ to 3.9), Pacific region (west) (OR 1.5; 95\% Cl 1.0 to 2.3), and belonging to the mestizo (others) ethnic group (OR 1.2; $95 \% \mathrm{Cl} 1.0$ to 2.6), were all associated with a higher probability of dietary supplement intake.

Conclusion: The prevalence of prenatal dietary supplements in pregnant women in Colombia was found to be substantial. The variables significantly associated with their use were educational level, socioeconomic level, trimester of pregnancy, geographic level and ethnic group. These results indicate the necessity of implementing new health policies that guarantee uniform access to nutritional supplements for all population sectors, especially in countries, such as Colombia, who are currently undergoing a process of nutritional transition.

Keywords: Nutrition, Pregnancy, Socio-demographic factors, Prenatal care, Prevalence

\section{Background}

Maternal nutrition plays a crucial role in influencing fetal growth and birth outcomes [1]. It is a modifiable risk factor of great importance in public health and is influential in the prevention of adverse birth outcomes, particularly in low-income populations [2]. Deficient dietary intake of vitamins and minerals has been associated with an increased risk of adverse birth outcomes (i.e.

\footnotetext{
* Correspondence: robin640@hotmail.com; robinson.ramirez@urosario.edu.co ${ }^{1}$ Centro de Estudios para la Medición de la Actividad Física «CEMA». Escuela de Medicina y Ciencias de la Salud, Universidad del Rosario, Bogotá D.C, Colombia

Full list of author information is available at the end of the article
}

miscarriage, low birth weight, preterm birth, and intrauterine growth restriction [IUGR]). Consequently, providing women with vitamin supplements either prior to or in early pregnancy may help prevent pregnancy complications [3].

Adverse birth outcomes are the leading cause of neonatal death among children born without congenital anomalies and often result in short-term and long-term health problems or disabilities, including a potential predisposition to chronic disease in adulthood [1]. Based on evidence from observational studies $[4,5]$, vitamin supplements, such as folate and B vitamins, are most

(c) The Author(s). 2018 Open Access This article is distributed under the terms of the Creative Commons Attribution 4.0 International License (http://creativecommons.org/licenses/by/4.0/), which permits unrestricted use, distribution, and 
frequently advocated for the prevention of adverse birth outcomes [6]. In addition, vitamins $\mathrm{A}, \mathrm{D}, \mathrm{E}$ and $\mathrm{C}$, iron, zinc, and selenium are the micronutrients that are generally provided as supplements during pregnancy.

Micronutrient needs increase during pregnancy because of changes in physiology and homeostatic control $[7,8]$. The importance of micronutrients has become increasingly apparent, especially in resource-poor settings in which women may enter pregnancy with multiple micronutrient deficiencies [9]. For example, in Colombia $38 \%$ of pregnant women have iron deficiency leading to anemia. This is especially prevalent in women of African descent, and those 18-29 years of age [10]. Moreover, $18 \%$ of pregnant women have vitamin B12 deficiency or folic acid [11], which can cause neural tube defects, such as spina bifida and anencephaly in the fetus. There is evidence that folic acid supplements during pregnancy decreases the risk of stillbirth, as shown in a comparative study of the use of low and high folic acid supplement dosages among pregnant women in Spain (RR 0.92, 95\% CI 0.85 to $0.99, n=79,851$ participants) [5]. Although the evidence base is not substantial for antioxidant vitamins, $\mathrm{A}$ and $\mathrm{C}$, a Cochrane review found no evidence of differences in early or late miscarriage between women given antioxidant vitamins compared to those in the low antioxidant group (RR 1.12, 95\% CI, 0.24 to 5.29 , one trial, 110 participants) [6].

Given the risk of malnutrition in low and middleincome countries, it is necessary to measure its prevalence in vulnerable populations, such as children [12], pregnant women $[9,10]$ and ethnic minorities [13] in order to identify high-risk groups and implement preventive interventions. Despite the fact that malnutrition during pregnancy is a major public health concern, little information is available regarding dietary supplement use in pregnant women throughout the world [14, 15]. Studies conducted in various countries suggest that prenatal dietary supplement use may be less frequent when the mother is younger, belongs to a low-income group, and has a low education level $[16,17]$. Currently, in Colombia, public health policies recommend prescribing iron, calcium and folic acid supplements during pregnancy [18].

However, to the best of our knowledge, research has never focused on the potential association between prenatal dietary supplement intake and socio-demographic factors in a nationally representative sample in Latin America. The results obtained could help identify risk groups, and thus provide information to better design interventions that would make the population aware of the need to take dietary supplements to meet nutritional needs.

For this reason, the objective of this study was to evaluate the prevalence and sociodemographic factors associated with dietary supplement intake in a representative sample of pregnant women in Colombia.

\section{Methods \\ Design and participants}

In National Nutritional Survey [Encuesta Nacional de la Situacion Nutricional en Colombia (ENSIN)], participants were selected through multi-stage stratified sampling to represent 99\% of the country's population [19]. Details of the survey have been published elsewhere $[10,11,19]$. The ENSIN survey included 50,670 households, in which 12,437 women of childbearing age (13-49 years), and 1856 (14.9\%) were pregnant (mean age of 24.4 years), completed a food frequency questionnaire. The databases were provided by the Colombian Institute of Family Welfare (in Spanish: Instituto Colombiano de Bienestar Familiar, ICBF), which is responsible for the ENSIN in Colombia. Consent for participation and databases were provided by the ICBF-ENSIN, from the website (https:// www.icbf.gov.co/bienestar/nutricion/encuesta-nacionalsituacion-nutricional).

All participants and the parents/legal guardians of minors under 18 gave their informed written consent before the study began. The PROFAMILIA Ethics Committee approved the study prior to data collection [Resolución 8430 de 1993; Ministerio de Salud de Colombia]. The study was conducted according to the guidelines in the Declaration of Helsinki.

\section{Data sources}

All information collected was obtained through face-toface interviews conducted at each site. The interview covered different aspects of pregnancy, including general information, sociodemographic variables, and dietary information. Use of prenatal micronutrients (such as Vitamin A and/or Vitamin C and/or Vitamin E) was treated as a binary outcome (at some time used or never used in pregnancy though always with a doctor's prescription) in all analyses.

The following sociodemographic variables were defined as associated factors: (i) age $(13-17,18-29$, or 30 49 years); (ii) pregnancy trimester (first, second, or third); (iii) education level (elementary and/or secondary, university and/or postgraduate); (iv) urbanicity (urban or rural); (v) ethnicity.

Ethnicity was divided into the following subgroups: (a) indigenous (indigenous ethnicity included 1,378,884 [3.4\%] people belonging to various groups, i.e. Emberá, Mokane, Ika, Kankuamo, Awuá, Misak, Nasa and Wayuu, [20]; (b) Black or Afro-Colombian; (c) others (e.g. mestizo). Mestizo Colombians have mixed European and Amerindian ancestry. They are the largest ethnic group in the country $(49 \%-58 \%$ of the population). 
Geographic region was divided into the following areas: (a) Atlantic (North); (b) Eastern; (c) Central; (d) Pacific (West); (e) Bogota; (f) National Territories comprising the departments of Putumayo, Amazonas, Arauca, Casanare, Guainía, Vichada, and Vaupés in the southern part of Colombia.

The socioeconomic status was determined according to the national SISBEN index (System of Identifying Potential Beneficiaries of Social Programs; SISBEN, initials for the Spanish) $[10,11,19]$. The SISBEN is a system designed by the Colombian Government to identify families who would benefit from social programs. Based on this information, six levels are defined with one being the poorest and six being the wealthiest. Households with SISBEN levels of I or II are regarded as the most vulnerable and are targeted in social programs. In contrast, a SISBEN level IV, (including levels IV-VI) is considered to be the least vulnerable sector of society [10, $11,19]$. For the purposes of this study, SISBEN scores were classified in four categories (I, II, III, and IV or higher) to improve the efficiency of the analyses.

\section{Data analysis}

Univariate tests were used to summarize and identify patterns in the data with a focus on the selected variables (Table 1). To investigate an association between prenatal supplement intake and multiple predictor variables (age, pregnancy trimester, education level, urbanicity, geographic region, ethnicity, and SISBEN socioeconomic level) we used a multilevel logistic regression model to estimate the magnitude of association in the form of odds ratios (ORs) and 95\% confidence intervals (CIs), between prenatal supplement intake and selected predictor variables. Additionally, we fitted two models. First, we included the gestational variables in the model (model 1: adjusted by age and trimester of pregnancy) to investigate the extent to which prenatal supplement intake differences were explained by the individual composition of the women. Second, we included the sociodemographic factors variables (model 2: education level, geographic area, socioeconomic level, and urbanicity). This was in addition to the variables already included in model 1 to discover whether this prenatal dietary supplement use was conditioned by specific sociodemographic characteristics. Variables with $P<$ 0.10 were considered for the multilevel logistic regression analysis. All analyses were performed with the use of the complex survey design routines of the SPSS Statistical software package version 20 (SPSS, Chicago, IL, USA).

\section{Results}

There were 1123 women ([68.6\%] 95\% CI, 67.2\% to 69.8\%) who reported taking prenatal dietary supplements at some stage during their pregnancy. Factors associated with a higher intake of dietary supplements were the following: (i) university or postgraduate education (82\%); (ii) third trimester of pregnancy (79.6\%); (iii) high socioeconomic level, SISBEN IV or higher (79.5\%); (iv) age of 30-49 years (74\%); (v) residence in a central region $(73.8 \%)$, and Atlantic region (71.7\%) of Colombia. In addition, pregnant women living in urban areas $(71.0 \%)$ and with an ethnicity of others (mestizo) also had a high prevalence of dietary supplement use (Table 1).

Figure 1 shows the results of the logistic regression analysis. Once the adjustment was performed (by age, pregnancy trimester, education level, geographic area, socioeconomic status, and urbanicity), a higher probability of prenatal supplement use was found to be associated with the following: (i) third trimester of pregnancy (OR 6.2;95\% CI 4.0 to 9.3), (ii) high educational level (OR 2.3; 95\% CI 1.5 to 3.4), (iii) high SISBEN IV or higher SES (OR 2.0; 95\% CI 1.4 to 2.8 ), (iv) residence in the Atlantic region (north) (OR 2.6; 95\% CI 1.7 to 3.6), (v) Eastern region (OR 2.0; 95\% CI 1.3 to 3.1), (vi) central region (OR 2.6; 95\% CI 1.7 to 3.9), (vii) Pacific region (west) (OR 1.5; 95\% CI 1.0 to 2.3), and (viii) being part of the mestizo (others) ethnic group (OR 1.2; 95\% CI 1.0 to 2.6).

\section{Discussion}

The results of this study show that a high percentage of women (68.6\%) affirmed that they had taken dietary supplements at some time during their pregnancy. This was particularly the case for women, who had a high socioeconomic status and education level, who lived in the central, pacific (west) or Atlantic (north) regions of Colombia, and who were in the third trimester of their pregnancy. Our results differ from those obtained by Titlayo et al. [21] in their study of pregnant women in Malawi, where only $37 \%$ of the subjects reported taking dietary supplements during their pregnancy. However, despite the generally lower consumption of these supplements among pregnant women in Malawi, factors that influenced their supplement intake during pregnancy included the participants' residence in an urban area as well as a high education and socioeconomic level. These coincided with the significant factors highlighted in our study and which reflect unequal access to these dietary supplements. In other words, pregnant women who would most benefit from taking these supplements are those that have fewer possibilities of obtaining them.

In this same line, Taye et al. [22] conducted a study of 634 Ethiopian women and observed that pregnant women with a high education level and socioeconomic status were more likely to adhere and comply with the regular use of dietary supplements. They probably had a better knowledge of and easier access to information regarding the importance and benefits derived from taking 
Table 1 Prevalence and socio-demographic factors associated with prenatal supplement intake in a representative sample of pregnant women in Colombia

\begin{tabular}{|c|c|c|c|c|}
\hline \multirow[t]{3}{*}{ Characteristics } & \multicolumn{4}{|c|}{ Prenatal supplement intake } \\
\hline & \multicolumn{2}{|c|}{ Yes } & \multicolumn{2}{|l|}{ No } \\
\hline & $\mathrm{n}(\% *)$ & $95 \% \mathrm{Cl}^{* *}$ & $\mathrm{n}\left(\%^{*}\right)$ & $95 \% \mathrm{Cl}^{* *}$ \\
\hline Total $(n=1865)$ & $1123(68.6)$ & $(67.2-69.8)$ & $742(31.4)$ & $(29.7-33.0)$ \\
\hline \multicolumn{5}{|l|}{ Age (years) } \\
\hline 13 to $17(n=249)$ & $142(65.6)$ & $(62.0-68.2)$ & $107(34.4)$ & $(30.0-37.5)$ \\
\hline 18 to $29(n=1204)$ & $727(67.4)$ & $(65.8-68.7)$ & 477 (32.6) & $(30.6-34.5)$ \\
\hline 30 to $49(n=412)$ & $254(74.0)$ & $(71.6-75.8)$ & $158(26.0)$ & $(22.9-28.5)$ \\
\hline \multicolumn{5}{|l|}{ Trimester of pregnancy } \\
\hline First $(n=292)$ & $96(41.3)$ & $(36.6-44.8)$ & $196(58.7)$ & $(55.8-60.8)$ \\
\hline Second $(n=978)$ & $602(69.3)$ & $(67.7-70.6)$ & $376(30.7)$ & $(28.5-32.7)$ \\
\hline Third $(n=595)$ & 425 (79.6) & $(78.1-80.8)$ & $170(20.4)$ & $(17.8-22.6)$ \\
\hline \multicolumn{5}{|l|}{ Education level } \\
\hline Elementary or secondary $(n=1537)$ & $864(64.6)$ & $(63.0-66.0)$ & $673(35.4)$ & $(33.6-37.0)$ \\
\hline University or postgraduate $(n=328)$ & $259(82.0)$ & $(80.6-83.1)$ & $69(18.0)$ & $(14.0-21.0)$ \\
\hline \multicolumn{5}{|l|}{ Socioeconomic level } \\
\hline Level I ( $n=1088)$ & $561(61.2)$ & $(59.2-62.9)$ & $527(38.8)$ & $(36.8-40.6)$ \\
\hline Level $\|{ }^{\mathrm{a}}(n=176)$ & $106(62.3)$ & $(58.3-65.0)$ & $70(37.7)$ & $(32.1-41.6)$ \\
\hline Level III ${ }^{\mathrm{a}}(n=136)$ & $98(77.1)$ & $(73.6-79.4)$ & $38(22.9)$ & $(17.2-26.6)$ \\
\hline Level IV or more $(n=465)$ & $358(79.5)$ & $(78.1-80.6)$ & $107(20.5)$ & $(17.5-23.0)$ \\
\hline \multicolumn{5}{|l|}{ Geographic area } \\
\hline Atlantic (North) $(n=438)$ & $302(71.7)$ & $(69.8-73.3)$ & $136(28.3)$ & $(25.6-30.5)$ \\
\hline Eastern $(n=258)$ & $179(69.2)$ & $(66.9-71.0)$ & 79 (30.8) & $(26.7-33.9)$ \\
\hline Central $(n=381)$ & $264(73.8)$ & $(71.5-75.5)$ & $117(26.2)$ & $(23.2-28.6)$ \\
\hline Pacific (West) $(n=246)$ & $128(59.0)$ & $(55.6-61.6)$ & $118(41.0)$ & $(37.8-43.5)$ \\
\hline Bogotá a $^{(n=98)}$ & $68(69.4)$ & $(65.9-71.8)$ & $30(30.6)$ & $(24.4-34.7)$ \\
\hline National territories (South) $(n=444)$ & $182(49.8)$ & $(46.3-52.6)$ & $262(50.2)$ & $(47.0-52.7)$ \\
\hline \multicolumn{5}{|l|}{ Urbanicity } \\
\hline Urban $(n=1186)$ & $804(71.0)$ & $(69.8-72.2)$ & $382(29.0)$ & $(26.8-30.9)$ \\
\hline Rural $(n=679)$ & $319(47.0)$ & $(58.9-64.1)$ & $360(53.0)$ & $(36.2-39.8)$ \\
\hline \multicolumn{5}{|l|}{ Ethnic group ${ }^{\neq}$} \\
\hline Indigenous ( $n=272$ ) & $95(50.2)$ & $(45.1-53.6)$ & $177(49.8)$ & $(44.1-53.6)$ \\
\hline Black or Afro-Colombian $(n=202)$ & $109(63.6)$ & $(59.4-66-6)$ & $93(36.4)$ & $(33.2-38.6)$ \\
\hline Others $(n=1380)$ & $908(70.3)$ & $(69.0-71.5)$ & $472(29.7)$ & $(27.8-31.4)$ \\
\hline
\end{tabular}

*All women analyzed by ethnic group were $n=1854$. Another two belonged to "Raizal del archipiélago", but they were not analyzed because this group did not have a representative sample

**It is not correct to calculate the percentages from the " $n$ " in this table. These calculations were taken from the weight of the values given to each subject *data from 1854 participants

a Since the coefficient of variation is more than $20 \%$ of the deficiency prevalence, the variation should be interpreted with caution

these supplements during pregnancy [23]. Furthermore, the reasons that could justify differences in supplement intake among pregnant women in rural and urban areas could be related to the inequality of opportunities, which is characteristic of low and middle-income countries such as Colombia. For this reason, women in urban areas doubtlessly have better access to health services than women in rural areas [21]. Therefore, in our study, women who had a low socioeconomic status and education level, were less likely to adhere and comply with the regular use of dietary supplements during pregnancy.

Previous studies also reported that pregnant women living in urban areas and in geographic regions with a higher level of structural and economic development show a greater adherence to health programs that include the prolonged intake of vitamin supplements 


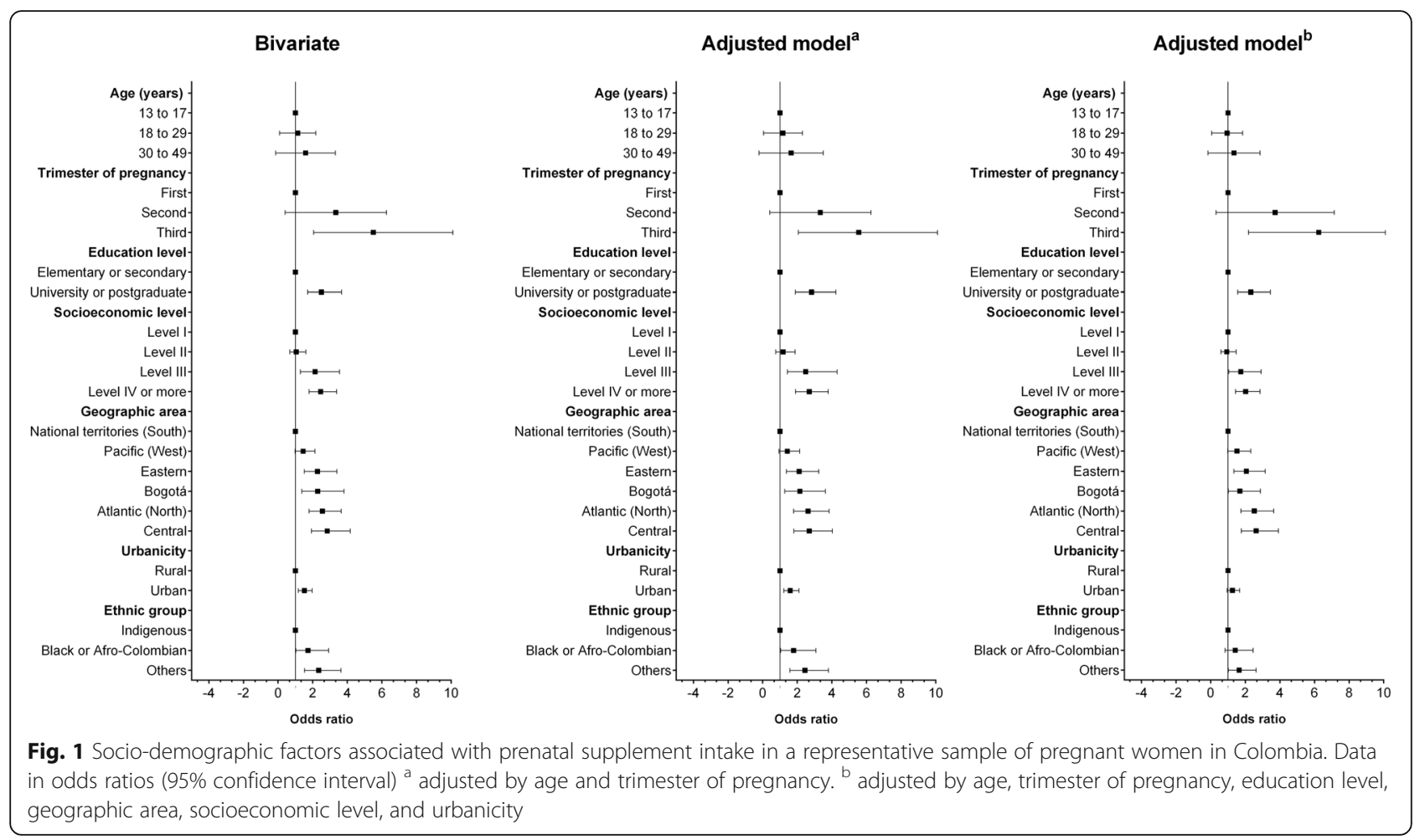

during pregnancy $[24,25]$. Moreover, ethnic group was another significant factor in relation to the use of dietary supplements by pregnant women in Colombia. In this regard, mestizo women maintained a more consistent pattern of vitamin intake. Other studies [26-28], show greater deficiencies in dietary supplementation in pregnant women belonging to ethnic minorities. In countries like Colombia where economic constraints place limits on achieving dietary adequacy, food-based interventions are one way of improving the nutritional status of vulnerable populations such as pregnant women.

As can be observed in the results of the adjusted regression analysis, pregnant women were found to be more likely to take prenatal dietary supplements if they were in the third trimester of pregnancy, had a higher education level, and resided in the Atlantic regions in north Colombia, pacific (west) region or in the central region of the country. These results are clinically and socially relevant for Colombia since, according to WHO [29], each pregnant woman should receive dietary supplements (i.e. vitamins and minerals) one month before conception until the end of the first pregnancy trimester though the current tendency is to prolong intake during the entire pregnancy.

However, the results obtained show that there was a greater probability of receiving supplements in the third trimester of pregnancy. In contrast, there was no guarantee of receiving essential vitamins and minerals in the other two trimesters of pregnancy [30]. This situation is troubling, especially if we consider that $18 \%$ of pregnant women in Colombia have anemia and 37\% suffer from iron deficiency [31]. These results indicate the necessity of implementing new health policies that guarantee uniform access to nutritional supplements for all population sectors [32].

Various studies have found that poor nutritional status at birth is associated with physical and cognitive impairments during infancy and childhood that may persist into adulthood [33-35]. Research on animals and epidemiological studies indicate that metabolic adaptations in suboptimal intrauterine environments are associated with the onset of cardiovascular disease, diabetes, and other chronic illnesses later in life [36]. These changes, referred to as fetal programming, underpin the "fetal origins of adult disease" hypothesis [37].

The results of our study highlight the fact that Colombia must implement interventions and/or reproductive health programs with a view to guaranteeing an all-encompassing obstetric care system. This includes meeting nutritional needs throughout the entire pregnancy, regardless of the education level or geographic location of the pregnant woman [38]. An effective strategy would thus be to follow the recommendations of the Grupo Asesor en Micronutrientes [Micronutrients Advisory Group] of MERCOSUR [39], which include a varied diet, iron supplements for pregnant women and children under two, and food fortification (i.e.: wheat flour, maize flour, and rice). Another important initiative is the 
program for the prevention and reduction of nutritional anemia devised and fostered by the President of Colombia, the Colombian Ministry of Health, and the United Nations World Food Program. The implementation of these measures would help to combat nutritional deficiencies in the general population, and especially in pregnant women independent of the education level and socioeconomic status.

The Colombian Ministry of Health has acknowledged the need to improve the nutritional status of women during pregnancy. Priorities of the Decanal National Public Health Strategy: 2012-2021 [40] include the "reduction of protein energy malnutrition and micronutrient deficiencies in women and improving care for pregnant women, including extra dietary intake and rest for increased weight gain during pregnancy". Key Colombia Ministry of Health recommendations for women during pregnancy are the following: (i) total weight gain of at least $7 \mathrm{~kg}$; (ii) consumption of one extra daily meal (unspecified); (iii) a course of 90 ironfolic acid tablets (provided at a prenatal care center); and (iv) a minimum of four prenatal care visits [41]. All these recommendations would be an important step towards improving the health of pregnant women and of unborn children. It would also help to reduce unequal access to nutritional resources and supplements.

Consequently, lessons learned from the Colombian context through analyses of available surveillance data as well as from the future process and impact evaluation of policies and programs have the potential to inform malnutrition prevention efforts in other settings. In Colombia, the following three strategies can be implemented to improve nutritional status: (i) dietary interventions that promote increased consumption of a greater variety of locally available nutritious foods; (ii) fortification of commonly consumed foods/seasonings; (iii) provision of nutritional supplements that help individuals achieve required intakes of certain nutrients often lacking in staple diets. For this reason, it is essential to educate health personnel about nutrition and nutritional needs. On a positive note, coordination with other educational and health and wellness strategies has produced viable and sustainable interventions [11]. This practice supports the Millennium Development Goals [42] to promote the health of mothers and infants in low and middle-income countries.

Our study has certain limitations. The most substantial limitation of this study was the source of denominator data. We examined the effect of the associated factors and made use of the best data available to estimate the population at risk for each age group. The distributions of women, 13-49 years of age, who were surveyed in the 2010 ENSIN data set, were applied to the 2009 population projections in Colombia. Given that the 2010
ENSIN was reported data, the distribution of the sociodemographic variables used to obtain the population at risk in our study was limited by the quality of the survey results. Difficulties in estimating risk-factor groupspecific denominator data for less populated regions also limited our ability to assess the joint effect of education and insurance in these data. Another limitation was the cross-sectional design that does not permit the establishment of causality.

One of the evident strongpoints of our study is the fact that it is the first one to assess the prevalence and socio-demographic factors associated with dietary supplement intake in Colombia in women, 13-49 years of age. For this purpose, multimodal regressions were used to control for confounding multiple socio-demographic variables and for missing values. Another strongpoint of this study is the size of the sample population, which can be used to make comparisons in subsequent studies. Furthermore, this study helps to remedy the lack of available information in Latin America with regard to the use of dietary supplements by pregnant women. In this regard, the results obtained are original as well as clinically and epidemiologically important.

\section{Conclusions}

The research results presented in this paper showed that during prenatal care in Colombia, there is a substantial use of dietary supplements in pregnant women with a high socioeconomic status and education level. Moreover, the high prevalence of supplement intake during pregnancy is significantly associated with factors such as high education level, third trimester of pregnancy, ethnic group, and geographic location. Our findings point to the need to further evaluate, foster, and enhance undernutrition prevention, diagnosis, treatment, and follow-up. Furthermore, these results indicate the necessity of implementing new health policies that guarantee uniform access to nutritional supplements for all population sectors, especially in countries, such as Colombia, who are currently undergoing a process of nutritional transition.

\section{Abbreviations}

ENSIN: 2000 Colombian National Nutrition Survey (initials for the Spanish); IUGR: Intrauterine growth restriction; PROFAMILIA: Asociación Pro-bienestar de la Familia Colombiana (in Spanish); SISBEN: System of Identifying Potential Beneficiaries of Social Programs (initials for the Spanish

\section{Acknowledgments}

We would like to thank all participants for their cooperation and participation in this survey. We also wish to thank Javier Martinez-Torres, MSc, for his assistance with statistical analysis.

\section{Funding}

The ENSIN was funded by the Colombian Institute of Family Welfare (ICBF, for its initials in Spanish) and was conducted during the years 2008-2010. The funding had no role in the study design, in the collection, analysis, and interpretation of data, in the writing of the manuscript, or in the decision to submit the manuscript for publication. 


\section{Availability of data and materials}

For the purposes of this study, permission was obtained from PROFAMILIAENSIN to use the publicly available data for research and teaching purposes. Further details can be obtained from the (https://www.icbf.gov.co/bienestar/ nutricion/encuesta-nacional-situacion-nutricional), the website of the association. The data will not be shared in order to protect the participants' anonymity.

\section{Authors' contributions}

RR-V and JEC-B: conception idea for the study, design of the study, data analysis, manuscript preparation and subsequent revisions. HRT-R and KG-R: advice in designing the study and analysis and revision of the manuscript. EG-J and JSR-V: conception of the research idea, advice in designing the study and analysis and revision of the manuscript. All authors read and approved the final manuscript.

\section{Ethics approval and consent to participate}

The study was conducted according to the guidelines in the Declaration of Helsinki. A comprehensive verbal description of the nature and purpose of the study and of its experimental risks was presented to all subjects. In the case of participants under 18, this information was provided to their parents/ guardians. All participants and the parents/legal guardians of minors under 18 gave their informed written consent before the study began. The PROFAMILIA Ethics Committee approved the study prior to data collection [Resolución 8430 de 1993; Ministerio de Salud de Colombia].

\section{Competing interests}

The authors declare that they have no competing interests.

\section{Publisher's Note}

Springer Nature remains neutral with regard to jurisdictional claims in published maps and institutional affiliations.

\section{Author details}

'Centro de Estudios para la Medición de la Actividad Física «CEMA». Escuela de Medicina y Ciencias de la Salud, Universidad del Rosario, Bogotá D.C, Colombia. ${ }^{2}$ Grupo GICAEDS. Programa de Cultura Física, Deporte y Recreación, Universidad Santo Tomás, Bogotá, D.C, Colombia. ${ }^{3}$ Departamento de Enfermería. Facultad de Ciencias de la Salud, Universidad de Granada, Avda. De la llustración, s/n, 18016 Granada, Spain. ${ }^{4}$ Departamento de Enfermería. Facultad de Ciencias de la Salud, Universidad de Granada, Grupo CTS-436, Centro de Investigación Mente Cerebro y Comportamiento (CIMCYC), Granada, Spain. ${ }^{5}$ Vicerrectoría de Investigaciones, Grupo de Ejercicio Físico y Deportes, Facultad de Salud, Universidad Manuela Beltrán, Bogotá, D.C, Colombia.

Received: 20 April 2017 Accepted: 22 April 2018

Published online: 02 May 2018

\section{References}

1. Abu-Saad K, Fraser D. Maternal nutrition and birth outcomes. Epidemiol Rev. 2010;32:5-25.

2. Fall CH, Yajnik CS, Rao S, Davies AA, Brown N, Farrant HJ. Micronutrients and fetal growth. J Nutr. 2003;133:1747-56.

3. Devakumar D, Fall CH, Sachdev HS, Margetts BM, Osmond C, Wells JC, et al. Maternal antenatal multiple micronutrient supplementation for long-term health benefits in children: a systematic review and meta-analysis. BMC Med. 2016;14(1):90

4. Lundqvist A, Sandström H, Stenlund H, Johansson I, Hultdin J. Vitamin D status during pregnancy: a longitudinal study in Swedish women from early pregnancy to seven months postpartum. PLoS One. 2016;11(3):e0150385.

5. Navarrete-Muñoz EM, Valera-Gran D, García de la Hera M, Gimenez-Monzo D, Morales E, Julvez J, et al. Use of high doses of folic acid supplements in pregnant women in Spain: an INMA cohort study. BMJ Open. 2015;5(11):e009202.

6. Balogun OO, da Silva Lopes K, Ota E, Takemoto Y, Rumbold A, Takegata M, et al. Vitamin supplementation for preventing miscarriage. Cochrane Database Syst Rev. 2016;5:CD004073.

7. Picciano MF. Pregnancy and lactation: physiological adjustments, nutritional requirements and the role of dietary supplements. J Nutr. 2003;133:1997-2002

8. Branum AM, Bailey $R$, Singer B. Dietary supplement use and folate status during pregnancy in the United States. J Nutr. 2013;143(4):486-92.
9. Berti C, Gaffey MF, Bhutta ZA, Cetin I. Multiple-micronutrient supplementation: evidence from large-scale prenatal programmes on coverage, compliance and impact. Matern Child Nutr. 2017;22 https://doi. org/10.1111/mcn.12531.

10. Ramírez-Vélez R, González-Ruíz K, Correa-Bautista J, Martínez-Torres J, Meneses-Echávez JF, Rincon-Pabon D. Ferritin levels in pregnant Colombian women. Nutr Hosp. 2014;31(2):793-7.

11. Ramírez-Vélez R, Correa-Bautista JE, Martínez-Torres J, Meneses-Echávez JF, Lobelo F. Vitamin B12 concentrations in pregnant Colombian women: analysis of nationwide data 2010. BMC Pregnancy Childbirth. 2016;16:26

12. Ramírez-Vélez R, Correa-Bautista JE, Martínez-Torres J, González-Ruíz K Lobelo F. Ferritin levels in Colombian children: findings from the 2010 National Nutrition Survey (ENSIN). Int J Environ Res Public Health. 2016;13(4)

13. Taksler GB, Cutler DM, Giovannucci E, Keating NL. Vitamin D deficiency in minority populations. Public Health Nutr. 2015;18(3):379-91.

14. McNally S, Bourke A. Periconceptional folic acid supplementation in a nationally representative sample of mothers. Ir Med J. 2012;105(7):236-8.

15. Jensen CB, Petersen SB, Granström C, Maslova E, Mølgaard C, Olsen SF. Sources and determinants of vitamin $D$ intake in Danish pregnant women. Nutrients. 2012;4(4):259-72

16. Kaiser L, Allen LH. American dietetic association. Position of the American dietetic association: nutrition and lifestyle for a healthy pregnancy outcome. J Am Diet Assoc. 2008;108:553-61.

17. Nisar YB, Dibley MJ, Mir AM. Factors associated with non-use of antenatal iron and folic acid supplements among Pakistani women: a cross sectional household survey. BMC Pregnancy Childbirth. 2014;14:305.

18. Flores Navarro-Pérez C, González-Jiménez E, Schmidt-RioValle J, MenesesEchávez JF, Martínez-Torres J, Ramírez-Vélez R. Sociodemographic factors and adequacy of prenatal care associated perinatal mortality in colombian pregnant women. Nutr Hosp. 2015:32(3):1091-8.

19. ICBF. Instituto Colombiano de Bienestar Familiar. Encuesta Nacional de la Situación Nutricional en Colombia. (Instituto Colombiano de Bienestar Familiar ICBF, ed.). Bogotá; 2010 https://www.icbf.gov.co/bienestar/ nutricion/encuesta-nacional-situacion-nutricional.

20. Profamilia. Encuesta Nacional en Demografía y Salud 2005 (ENDS 2005) Resultados Generales; 2005. https://formularios dane.gov.co/Anda 4 1/ index.php/catalog/465

21. Titilayo A, Palamuleni ME, Omisakin O. Sociodemographic factors influencing adherence to antenatal iron supplementation recommendations among pregnant women in Malawi: analysis of data from the 2010 Malawi demographic and health survey. Malawi Med J. 2016;28(1):1-5.

22. Taye B, Abeje G, Mekonen A. Factors associated with compliance of prenatal iron folate supplementation among women in Mecha district, western Amhara: a cross-sectional study. Pan Afr Med J. 2015;20:43.

23. Lawal TA, Adeleye AO. Determinants of folic acid intake during preconception and in early pregnancy by mothers in Ibadan, Nigeria. Pan Afr Med J. 2014;19:113.

24. Jones KM, Ramirez-Zea M, Zuleta C, Allen LH. Prevalent vitamin B12 deficiency in twelve-month-old Guatemalan infants is predicted by maternal B12 deficiency and infant diet. J Nutr. 2007:137:1307-13.

25. Gröber U, Kisters K, Schmidt J. Neuroenhancement with vitamin B12-underestimated neurological significance. Nutrients. 2013;5:5031-45.

26. Howell SR, Barnett AG, Underwood MR. The use of preconceptional folic acid as an indicator of uptake of a health message amongst white and Bangladeshi women in tower hamlets, East London. Fam Pract. 2001;18(3):300.

27. Bakker MK, Cornel MC, Awareness DWHEK. Periconceptional use of folic acid among non-western and western women in the Netherlands following the 1995 publicity campaign. Ned Tijdschr Geneeskd. 2003;147:2426-30.

28. Baraka MA, Steurbaut S, Leemans L, Foulon W, Laubach M, Coomans D, Jansen E, Dupont AG. Determinants of folic acid use in a multi-ethnic population of pregnant women: a cross-sectional study. J Perinat Med. 2011;39(6):685-92

29. WHO. The prevalence of anemia in women: a tabulation of available information. Ginebra: Organización Mundial de la Salud; 1992.

30. López Rodríguez MJ, Sánchez Méndez JI, Sánchez Martínez MC, Calderay DM. Suplementos en embarazadas: controversias, evidencias y recomendaciones. Inf Ter Sist Nac Salud. 2010;34:117-28.

31. Instituto Colombiano de Bienestar Familiar. Valoración del estado nutricional por indicadores bioquímicos. In: Encuesta nacional de la situación nutricional en Colombia, vol. 2010. Bogotá D.C.: ICBF; 2011. p. 171.

32. Ramírez-Vélez R, Matínez-Torres J, Meneses-Echavez JF. Prevalence and demographic factors associated with ferritin deficiency in Colombian children, 2010. Rev Peru Med Exp Salud Publica. 2014;31(2):237-42. 
33. Delpierre C, Fantin R, Barboza-Solis C, Lepage B, Darnaudéry M, Kelly-Irving $M$. The early life nutritional environment and early life stress as potential pathways towards the metabolic syndrome in mid-life? A lifecourse analysis using the 1958 British birth cohort. BMC Public Health. 2016;16(1):815.

34. Nnam NM. Improving maternal nutrition for better pregnancy outcomes. Proc Nutr Soc. 2015;74(4):454-9.

35. Shin D, Bianchi L, Chung H, Weatherspoon L, Song WO. Is gestational weight gain associated with diet quality during pregnancy? Matern Child Health J. 2014;18(6):1433-43.

36. Haimov-Kochman R. Fetal programming the intrauterine origin of adult morbidity. Harefuah. 2005;144(2):97-101.

37. Ramírez-Vélez R. In utero fetal programming and its impact on health in adulthood. Endocrinol Nutr. 2012;59(6):383-93.

38. Sarmiento OL, Ramirez A, Kutschbach BS, Pinzón PL, García S, Olarte AC, et al. Nutrition in Colombian pregnant women. Public Health Nutr. 2012;15:955-63.

39. Estrategia nacional para la prevención y control de las deficiencias de micronutrientes en Colombia 2014 - 2021. Ministerio de Salud y Protección Social. Bogotá, D.C. Colombia; 2015. [12-04-2018]. https://www.minsalud. gov.co/sites/rid/Lists/BibliotecaDigital/RIDE/NS/PP/SNA/Estrategia-nacionalprevencion-control-deficiencia-micronutrientes.pdf.

40. Sistema de Nacional de Seguimiento y Evaluación del Plan Decenal de Salud Pública 2012-2021. http://www.sispro.gov.co/Pages/Observatorios/ pds.aspx.

41. Manual de Control prenatal colombia ministerio de proteccion social. 2016. http://www.colombianadesalud.org.co/PROMOCION_PREVENCION/ INSTRUCTIVOS\%20PYP/OKPROTOCOLO\%20CONTROL\%20PRENATAL.pdf

42. McLean $E$, de Benoist B, Allen LH. Review of the magnitude of folate and vitamin B12 deficiencies worldwide. Food Nutr Bull. 2008;29(Suppl 2):38-51.

\section{Ready to submit your research? Choose BMC and benefit from:}

- fast, convenient online submission

- thorough peer review by experienced researchers in your field

- rapid publication on acceptance

- support for research data, including large and complex data types

- gold Open Access which fosters wider collaboration and increased citations

- maximum visibility for your research: over $100 \mathrm{M}$ website views per year 